Old Dominion University

ODU Digital Commons

\title{
Phenotypic Variation of Partridge Pea (Chamaecrista fasciculata) from Mississippi Persists in a Common Garden
}

Lisa E. Wallace

Old Dominion University, lewallac@odu.edu

Mahboubeh Hosseinalizadeh-Nobarinezhad

Robert Coltharp

Follow this and additional works at: https://digitalcommons.odu.edu/biology_fac_pubs

Part of the Biology Commons, and the Botany Commons

\section{Original Publication Citation}

Wallace, L. E., Hosseinalizadeh-Nobarinezhad, M., \& Coltharp, R. (2020). Phenotypic variation of partridge pea (Chamaecrista fasciculata) from Mississippi persists in a common garden. Castanea, 85(1), 93-107. https://doi.org/10.2179/0008-7475.85.1.93

This Article is brought to you for free and open access by the Biological Sciences at ODU Digital Commons. It has been accepted for inclusion in Biological Sciences Faculty Publications by an authorized administrator of ODU Digital Commons. For more information, please contact digitalcommons@odu.edu. 


\title{
Phenotypic Variation of Partridge Pea (Chamaecrista fasciculata) from Mississippi Persists in a Common Garden
}

\author{
Lisa E Wallace ${ }^{1 *}$, Mahboubeh Hosseinalizadeh-Nobarinezhad ${ }^{2}$, and Robert Coltharp ${ }^{2}$ \\ 1'Department of Biological Sciences, Old Dominion University, Norfolk, VA 23529 \\ ${ }^{2}$ Department of Biological Sciences, Mississippi State University, Mississippi State, MS 39762
}

\begin{abstract}
Intraspecific phenotypic variation occurs for many different reasons and understanding its basis has applications in taxonomy, ecology, and evolution. Chamaecrista fasciculata (partridge pea) is a widely distributed species with much phenotypic variation and varied interactions with other species in communities where it grows. Botanists have often noted that phenotypic variation in some traits of this species increases from north to south in the eastern United States. In this study, we grew seeds collected from five Mississippi populations in a common greenhouse environment to determine if the observed variation in leaf and stem traits is maintained in this environment. Interpopulation variation in the greenhouse-grown plants was not as extensive as that observed under natural conditions, but significant differences were detected in the number of stems and leaves and shoot height. The number of flowers and final shoot weight of plants did not differ, suggesting that there may be multiple growth strategies for this species to achieve equal fitness. Variation was detected in stem and leaflet trichome density. The population collected at the lowest latitude showed the most distinct morphology, producing shorter plants with many branched stems, more leaves, and a higher degree of leaflet pubescence. Trait variation that has so often been observed in natural populations of this species is maintained in a common environment, suggesting a genetic basis for the observed variation. Phenotypic variation observed in this species may reflect both responses to varied selective pressures from interacting species and adaptation to differing climatic factors.
\end{abstract}

Key words: Chamaecrista fasciculata, Common garden, latitudinal variation, leaf pubescence

\section{INTRODUCTION}

Phenotypic variation within species has long been of interest in evolutionary biology because it is the raw material upon which natural selection acts and plays an important role in species fitness and diversification. Additionally, there is an increasing awareness of the importance of phenotypic variation outside of evolutionary biology because of implications for conservation of rare species, management of non-native species, epidemiology of pathogens (Forsman 2014), and in the function and health of ecosystems (des Roches et al. 2018).

Phenotypic variation can arise from the expression of genetic variants, from environmental influence on genes, or some combination of these. When a genotype exhibits variability in its phenotype under different environmental conditions, it is known as phenotypic plasticity (Pigliucci et al. 2006). This contrasts with heritable genetic variation underlying phenotypic traits, in which case traits should remain constant in varying environments. Plasticity as a hypothesis for phenotypic variation can be tested through common garden experiments in which varying phenotypes are grown in the same environment (Martin et al. 2007, Kovnat and Porter 2016, Gao et al. 2018). If the same phenotypic traits persist in the common garden, the trait is expected to be genetic and heritable. If traits are

*email address: lewallac@odu.edu

Received 11 July 2019; Accepted 7 January 2020 
altered in the common garden, then a plastic basis is expected. Phenotypic variation in functional traits can influence an individual's fitness and shape how species interact in communities. Thus, quantifying functional genetic variation across landscapes can help in understanding the drivers of adaptation.

In this study, we used a common garden approach to evaluate the hypothesis of plasticity as the reason for observed phenotypic variation in partridge pea [Chamaecrista fasciculata (Michx.) Greene, Fabaceae]. Partridge pea is a widespread legume species of the eastern United States (USDA 2019) and a prominent member of many grassland, riparian, and upland communities. This species provides cover, nectar, and pollen for animals and contributes nitrogen to soils through its interactions with symbiotic rhizobia. Phenotypic variation in C. fasciculata has often been noted at local scales (e.g., Pullen 1963, Weakley 2015) and found to occur among geographically disparate populations (e.g., Galloway and Fenster 2000, Etterson 2004, Henson et al. 2013, Wallace, personal observation). While these observations suggest great potential for populations to be locally adapted, we have been unable to identify strong genetic differentiation at microsatellite loci among phenotypically diverse populations (Hosseinalizadeh-Nobarinezhad and Wallace, unpublished data). A deeper understanding of the nature of phenotypic variation in this species has bearing on its taxonomy and in evaluating how it interacts with other community members across the landscape. In this study we addressed three questions: 1 ) is natural variation in phenotypic traits maintained by $C$. fasciculata in a common garden; 2) is the variation in phenotypic traits correlated; and 3) are phenotypic variants geographically structured.

\section{MATERIALS AND METHODS}

To provide a comparison of phenotypic variation in natural populations, we measured four traits (i.e., shoot height, number of leaves, stems, and flowers) on 30 plants in each of five populations spanning latitude 31.05664 to 34.98542 in Mississippi (Figure 1) in July and September 2017. These traits were selected because they represent natural variation noted in the field across populations by Wallace et al. (unpublished data). In October 2017, a single ripe fruit was collected from each of 30 plants in each of the five populations. Seeds were removed from fruits, mixed with others from the same population, and stored in silica gel at $4^{\circ} \mathrm{C}$ until May 2018. At this time, approximately 50 randomly selected seeds from each population were scarified by rubbing the seed coat lightly with sandpaper. Seeds were then placed on wet tissues in petri dishes (one per population) to germinate in a windowsill in the lab. Once cotyledons appeared, seedlings were selected in pairs for planting in a one-gallon pot containing Premier Horticulture (Quakertown, Pennsylvania) 3.8-CF Pro Mix HP High Porosity with Mycorise soil. Seedlings continued to germinate in petri dishes for approximately 30 days and were transferred to pots. Overall, germination rates were low in all populations, and some seedlings did not survive transplanting into soil pots. The surviving seedlings were distributed across 10 replicate pots per population and set up in a randomized complete block design in the Biological Sciences greenhouse at Old Dominion University. Plants were watered by mist every six hours and $10 \mathrm{~mL}$ of a general fertilizer (N-P-K:24-8-16) was applied in 50\% concentration every 30 days. Although this species is naturally symbiotic with rhizobia, no inoculant was provided to them for this experiment because we have observed that establishment of rhizobia symbioses can be highly variable among plants grown in a greenhouse and in the field (Coltharp and Wallace, unpublished data). Therefore, we did not want to introduce an additional uncontrolled variable of rhizobia into the experimental design. Plants were maintained under natural light conditions for Norfolk, Virginia (i.e., without the additional of artificial light).

Data were recorded every two weeks from July 20-October 12 on the following traits: number of leaves, number of stems, shoot height from the soil to the apical meristem, and number of flowers present on the date of collection. On November 1, plants were harvested, and the roots removed. Fresh shoot weight was determined, followed by dry weight after drying in an oven at $60^{\circ} \mathrm{C}$ for one week. To determine trichome density for each plant, three leaflets and three internodes were selected, rehydrated in boiling water, and examined using a stereomicroscope. Due to difficulty in 


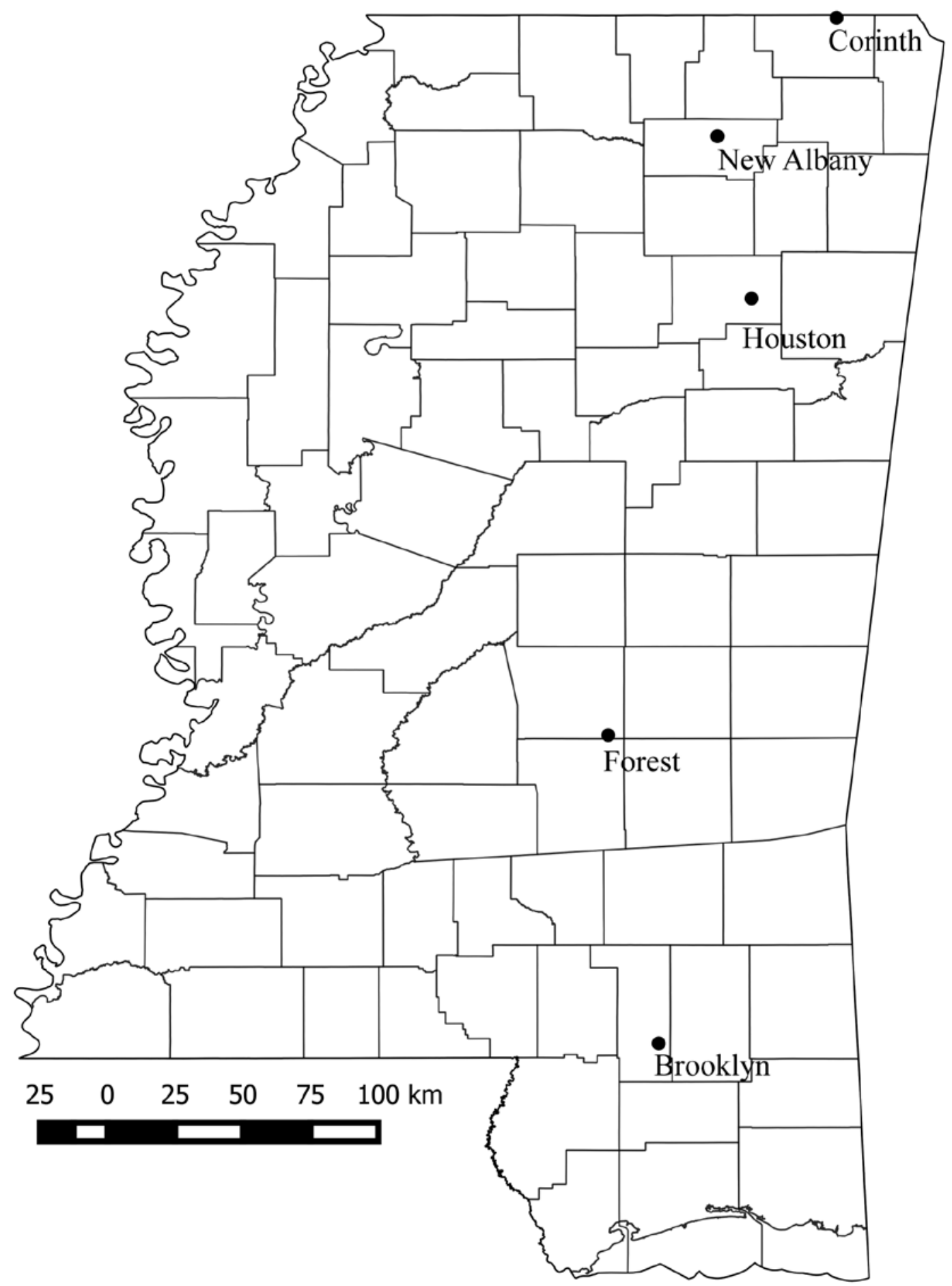

Figure 1. Locations of populations of Chamaecrista fasciculata (Michx.) Greene (Fabaceae) sampled in Mississippi. 
counting individual trichomes on the surface, trichome density of the stems and leaflets was characterized categorically as none-little, intermediate, or heavy. The basis for this categorical classification was observation of the number of trichomes in a section of leaflet between two major veins originating from the midvein (ca. $2 \mathrm{~mm}^{2}$ ) in the middle of the leaflet using $10 \times$ magnification with a Martin (Easley, South Carolina) stereomicroscope. A similar coding of trichome density was used on the primary stem. If the section contained $0-1$ visible trichomes, then it was scored as none-little, $2-10$ trichomes then it was intermediate, and more than 10 trichomes then it was heavy. There was strong consistency among independently scored leaflets or stems for all plants, thus each plant was recorded as having one of the three categories of trichome density for each of these traits.

Differences in phenotypic traits measured in the field in 2017 were tested for each date using oneway ANOVA with Tukey HSD post-hoc tests, rather than repeated measures because the same plants were not sampled on the two dates. For plants included in the common garden experiment, we tested for differences in leaf, stem, and flower number, as well as stem height across sampling dates and populations using repeated measures ANOVA with Tukey HSD post-hoc tests. Differences in final wet and dry weight of plants in the common garden experiment were assessed using one-way ANOVA. The proportion of plants exhibiting each category of trichome density on the leaflets and stems was determined for each population, and dependence between population of origin and trichome density was determined using a G-test of Independence. Pearson's correlation coefficient was used to determine if the traits showed significant associations. Linear regression analyses were used to determine if phenotypic traits of plants in the common garden experiment and in natural populations vary by latitude of origin. Data on traits measured in October (greenhouse) or September (natural) were used in these analyses. ANOVA, correlation, and regression analyses were conducted in SPSS v24 (IBM Corporation 2016). The G-test was conducted by hand.

\section{RESULTS}

Plants measured in the field exhibited significant variation in phenotypic traits across populations for all traits (Table 1; Figure 2). In these populations latitude was significantly associated with the number of leaves and stems, resulting in increases in these trait values with decreasing latitude (Table 2). We also observed earlier flowering in populations at higher latitudes as the two southernmost populations did not contain any flowers in July. By September, there were few differences in flower number, with only the Houston population varying from the Brooklyn, Forest, and New Albany populations in flower number.

The number of plants per population surviving to the end of the common garden experiment ranged from six to 17 (Table 3). Seedlings grown in this experiment exhibited similar variation in phenotypic traits to that observed in natural populations, but trait values often exceeded those from individuals measured in the field (Figures 2 and 3). Repeated measures ANOVA indicated a significant effect of date and date $\times$ population for mean shoot height, number of stems, and number of leaves (Table 4, Figure 3). Number of flowers differed significantly by date but not by population. The cumulative number of flowers recorded did not differ significantly across populations either $\left(\mathrm{F}_{4,50}=0.587 ; \mathrm{p}=0.7\right)$. Although neither of these measures accounts for flowers that were produced and dropped off between data collection dates, there was no reason to believe that the rate of flower production or senescence varied substantially across the populations in the common garden.

Two growth types were observed among populations in the greenhouse. Plants from the southernmost population exhibited a greater number of stems and leaves compared to plants from all other populations, and this effect was observed from the earliest growth stages to the end of the experiment. These plants also exhibited shorter overall height, but there was more variation in this trait than for stems and leaves within and across populations. Populations at higher latitudes in northern Mississippi began flowering earlier, but this did not seem to affect subsequent flower production. Despite differences in growth form, there was not a significant difference in wet $\left(\mathrm{F}_{4,50}=0.301, \mathrm{p}=0.9\right)$ or dry weight $\left(\mathrm{F}_{4,50}=0.330, \mathrm{p}=0.8\right)$ among populations at the end of the study. 
Table 1. Results from Analyses of Variance of four phenotypic traits measured on 30 plants in each of five populations of Chamaecrista fasciculata (Michx.) Greene (Fabaceae) spanning the south to north axis of eastern Mississippi. Data were collected in the field in July and September 2017.

\begin{tabular}{|c|c|c|c|c|c|}
\hline & Source & df & MS & $\mathbf{F}$ & p-value \\
\hline \multicolumn{6}{|l|}{ July } \\
\hline \multirow[t]{2}{*}{ Shoot height } & Population & 4 & 5554.223 & 39.766 & $<0.001$ \\
\hline & Error & 145 & 139.672 & & \\
\hline \multirow[t]{2}{*}{ Number of stems } & Population & 4 & 235.407 & 25.567 & $<0.001$ \\
\hline & Error & 145 & 9.207 & & \\
\hline \multirow[t]{2}{*}{ Number of leaves } & Population & 4 & 5197.460 & 22.360 & $<0.001$ \\
\hline & Error & 145 & 232.442 & & \\
\hline \multirow[t]{2}{*}{ Number of flowers } & Population & 4 & 17.177 & 14.319 & $<0.001$ \\
\hline & Error & 145 & 1.200 & & \\
\hline \multicolumn{6}{|l|}{ September } \\
\hline \multirow[t]{2}{*}{ Shoot height } & Population & 4 & 4660.857 & 14.420 & $<0.001$ \\
\hline & Error & 145 & 323.214 & & \\
\hline \multirow[t]{2}{*}{ Number of stems } & Population & 4 & 834.677 & 35.216 & $<0.001$ \\
\hline & Error & 145 & 23.702 & & \\
\hline \multirow[t]{2}{*}{ Number of leaves } & Population & 4 & 3719.173 & 8.595 & $<0.001$ \\
\hline & Error & 145 & 432.705 & & \\
\hline \multirow[t]{2}{*}{ Number of flowers } & Population & 4 & 131.323 & 2.971 & 0.021 \\
\hline & Error & 145 & 44.203 & & \\
\hline
\end{tabular}

Differences were found in pubescence on the stems and leaflets across populations (Table 3), and the G-test indicated a significant association between population of origin and trichome density of both stems $(p<0.001)$ and leaflets $(p<0.001)$. Heavy leaflet pubescence was rare in most populations, except the southernmost population. Most of the traits exhibited significant $(p<0.05)$ pairwise correlations, ranging from -0.275 between plant height and number of stems to 0.896 between number of stems and leaves (Table 5). Regression analyses indicated a significant association between the phenotypic traits and latitude of population of origin for shoot height, number of leaves, and number of stems, but not for number of flowers or final wet or dry weight based on the greenhouse plants (Table 2).

\section{DISCUSSION}

Common garden experiments inform understanding of local adaptation because they can exclude phenotypic plasticity as a reason for intraspecific variation (de Villemereuil et al. 2016). In this study, we documented variation in phenotypic traits of partridge pea growing in natural field conditions and demonstrated that much of this variation across populations is maintained in a common growing environment. These results suggest a genetic basis for trait variability, rather than a plastic response in partridge pea. Numerous botanists have discussed phenotypic variation present in C. fasciculata, particularly in the southernmost areas of the eastern United States For example, Pullen (1963) recognized eight varieties within $C$. fasciculata, Isley (1975) noted four varieties within the species and greatest phenotypic diversity across the southern Coastal Plain, and Robertson and Lee (1976) described C. fasciculata as a species complex of eight taxa. Pullen's (1963) work also included a common garden experiment in which he reported that stem branching could easily be modified under cultivation, but he also found many intraspecific crosses incompatible, which suggests genetic divergence among phenotypically diverse populations. Rios et al. (2008) quantified differences in traits of the extrafloral nectaries (EFN) of partridge pea in Missouri and Illinois, showed that variation is maintained in a common garden, and cited effects from herbivore variability as a reason behind variation in EFN's. Thus, multiple studies support the hypothesis of heritable variation in numerous traits of partridge pea across its geographic distribution.

For all traits except shoot height we found higher values in plants grown under greenhouse conditions in Virginia than in plants grown in natural conditions in Mississippi at times when plants 
A) July
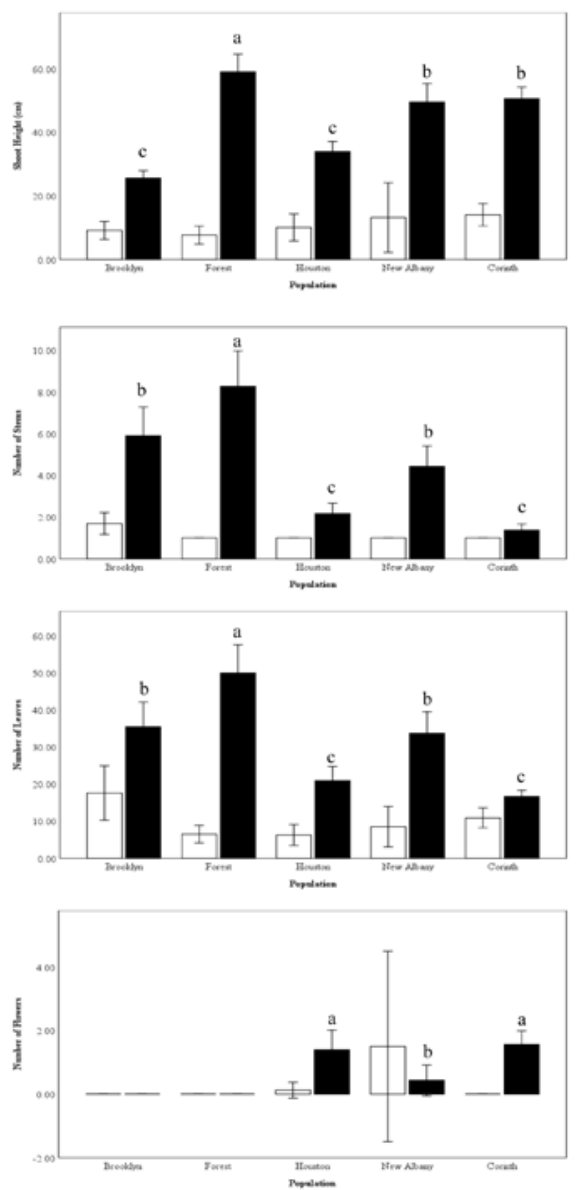

B) September/ October
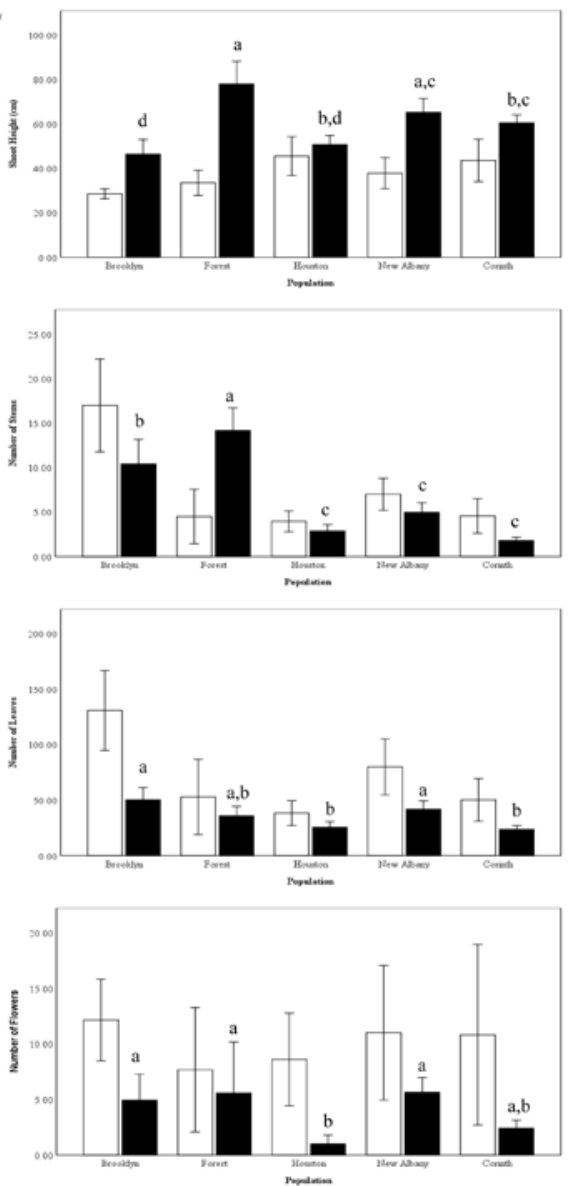

Figure 2. Mean values for four phenotypic traits measured on Chamaecrista fasciculata (Michx.) Greene (Fabaceae) plants growing in the greenhouse (white bars) and in natural populations (black bars) over two time points in the growing season. Data were collected in July (A) in natural populations and the greenhouse and in September or October (B) in natural populations and the greenhouse, respectively. Significantly different means for each trait among natural populations are indicated by unlike letters above bars. See Figure 3 for differences in trait values among greenhouse populations.

would have been well-established (Figure 2). This result is likely due to differences in resource availability, particularly associated with greater water and nutrients in the greenhouse. The degree of plasticity in traits between the field and greenhouse varied by population and trait. For example, the Forest population in southern Mississippi exhibited greater differences in shoot height and number of stems compared to other populations, the Brooklyn population exhibited greatest plasticity in number of leaves, and the Houston and Corinth populations exhibited the greatest plasticity in number of flowers (Figure. 2). Variation in plasticity among populations is expected to reflect localized strategies that are shaped at small spatial scales by unique biotic and abiotic factors as well as growing conditions at the time of sampling.

Whereas flowers produced varied significantly across populations in the field, it was not significantly different in the greenhouse study. At the later date, a greater number of flowers was recorded in the greenhouse than in the field (Figure 2). Reproductive output can be influenced by pollination rate, leading to a greater production of flowers, including buds, when fruits are not formed (Colosi and Cavers 1984, Stanton et al. 1987, Ackerman 1989, Ashman 1992). A similar situation may occur 
Table 2. Results of linear regressions of the association between latitude and phenotypic traits of Chamaecrista fasciculata (Michx.) Greene (Fabaceae) measured in September 2017 on plants in natural populations in Mississippi and in October 2018 on greenhouse-grown plants.

\begin{tabular}{|c|c|c|c|c|c|c|c|c|}
\hline \multirow{2}{*}{\multicolumn{2}{|c|}{$\frac{\text { Trait }_{\text {Natural Populations-2017 }} \text { Coefficient }^{1}}{\text { Nations }}$}} & \multirow[t]{2}{*}{ SE } & \multirow[t]{2}{*}{$\mathbf{t}$} & P-value & \multicolumn{2}{|c|}{ R-square } & & \\
\hline & & & & & & & & \\
\hline Height & & & & \multicolumn{2}{|r|}{0.084} & 1.160 & 1.031 & 0.304 \\
\hline 0.007 & & & & & & & & \\
\hline Stems & & & & \multirow{2}{*}{\multicolumn{2}{|c|}{-0.586}} & 0.303 & -8.809 & $<0.001$ \\
\hline 0.344 & & & & & & & & \\
\hline Leaves & & & & \multicolumn{2}{|r|}{-0.308} & 1.206 & -3.942 & $<0.001$ \\
\hline 0.095 & & & & & & & & \\
\hline Flowers & & & & \multicolumn{2}{|r|}{-0.125} & 0.376 & -1.529 & 0.128 \\
\hline \multicolumn{9}{|l|}{0.016} \\
\hline \multicolumn{9}{|c|}{ Greenhouse-2018 } \\
\hline Height & & & & \multirow{2}{*}{\multicolumn{2}{|c|}{0.584}} & 1.047 & \multirow[t]{2}{*}{5.182} & \multirow[t]{2}{*}{$<0.001$} \\
\hline 0.341 & & & & & & & & \\
\hline Stems & & & & \multirow{2}{*}{\multicolumn{2}{|c|}{-0.549}} & 0.590 & \multirow{2}{*}{-4.740} & \multirow[t]{2}{*}{$<0.001$} \\
\hline 0.302 & & & & & & & & \\
\hline Leaves & & & & \multirow{2}{*}{\multicolumn{2}{|c|}{-0.475}} & 4.615 & \multirow[t]{2}{*}{-3.895} & \multirow[t]{2}{*}{$<0.001$} \\
\hline 0.226 & & & & & & & & \\
\hline Flowers & & & & \multicolumn{2}{|r|}{0.035} & 0.902 & \multirow[t]{2}{*}{0.252} & \multirow[t]{2}{*}{0.80} \\
\hline 0.001 & & & & & & & & \\
\hline Wet weigh & & & & \multirow{2}{*}{\multicolumn{2}{|c|}{0.052}} & 0.311 & \multirow[t]{2}{*}{0.378} & \multirow[t]{2}{*}{0.71} \\
\hline 0.003 & & & & & & & & \\
\hline Dry weigh & 0.103 & 0.099 & 0.752 & 0.45 & 0.011 & & & \\
\hline
\end{tabular}

Height $=$ shoot height; Stems = number of stems; Leaves = number of leaves; Flowers = number of flowers.

${ }^{1}$ Standardized coefficients are reported.

Table 3. Sample sizes, mean final fresh and dry shoot weight, and pubescence of plants from five populations of Chamaecrista fasciculata (Michx.) Greene (Fabaceae) from Mississippi included in the common garden (greenhouse) experiment.

\begin{tabular}{|c|c|c|c|c|c|c|c|}
\hline Population & $\begin{array}{l}\text { GPS } \\
\text { Coordinates }\end{array}$ & County & $\mathbf{N}$ & $\begin{array}{l}\text { Fresh } \\
\text { Weight } \\
\text { ( } \pm \text { SE) }\end{array}$ & $\begin{array}{l}\text { Dry } \\
\text { Weight } \\
\text { ( } \pm \text { SE) }\end{array}$ & $\begin{array}{l}\text { Stem } \\
\text { pubescence }^{1}\end{array}$ & $\begin{array}{l}\text { Leaflet } \\
\text { pubescence }^{2}\end{array}$ \\
\hline Brooklyn & $\begin{array}{l}31.05664, \\
-89.18972\end{array}$ & Forrest & 13 & $6.18(0.99)$ & $1.74(0.31)$ & $4-8-1$ & $0-2-11$ \\
\hline Forest & $\begin{array}{l}32.23748 \\
-89.38297\end{array}$ & Scott & 10 & $4.91(1.30)$ & $1.48(0.42)$ & $3-4-3$ & $7-2-1$ \\
\hline Houston & $\begin{array}{l}33.9105 \\
-88.8344\end{array}$ & Chickasaw & 17 & $6.24(0.86)$ & $1.93(0.28)$ & $4-11-2$ & $17-0-0$ \\
\hline New Albany & $\begin{array}{l}34.53202 \\
-88.96492\end{array}$ & Union & 6 & $6.07(1.10)$ & $1.78(0.30)$ & $0-2-4$ & $6-0-0$ \\
\hline Corinth & $\begin{array}{l}34.98541 \\
-88.50894\end{array}$ & Alcorn & 9 & $6.30(0.74)$ & $1.96(0.27)$ & $0-0-9$ & $8-1-0$ \\
\hline
\end{tabular}

${ }^{1}$ Stem pubescence is given as number of individuals recorded as having little-some-heavy trichome density

${ }^{2}$ Leaflet pubescence is given as number of individuals recorded as having little-some-heavy trichome density 
Table 4. Results from repeated measures ANOVA of the four measured phenotypic traits recorded on Mississippi plants of Chamaecrista fasciculata (Michx.) Greene (Fabaceae) included in the common garden (greenhouse) experiment.

\begin{tabular}{|c|c|c|c|c|c|}
\hline Trait & Source & df & MS & $\mathbf{F}$ & p-value \\
\hline \multicolumn{6}{|c|}{ Height } \\
\hline & WithinDate & 5 & 5088.8 & 132.4 & $<0.001$ \\
\hline & Date $\times$ Pop & 20 & 152.4 & 3.9 & $<0.001$ \\
\hline & Error & 210 & 38.4 & & \\
\hline & Between Pop & 4 & 2005.0 & 6.3 & $<0.001$ \\
\hline & Error & 42 & 320.4 & & \\
\hline \multicolumn{6}{|l|}{ Stems } \\
\hline & Within Date & 5 & 246.5 & 27.4 & $<0.001$ \\
\hline & Date $\times$ Pop & 20 & 47.1 & 5.2 & $<0.001$ \\
\hline & Error & 210 & 9.0 & & \\
\hline & Between Pop & 4 & 906.8 & 9.7 & $<0.001$ \\
\hline & Error & 42 & 93.6 & & \\
\hline \multicolumn{6}{|c|}{ Leaves } \\
\hline & Within Date & 5 & 24704.2 & 64.5 & $<0.001$ \\
\hline & Date $\times$ Pop & 20 & 1795.2 & 4.7 & $<0.001$ \\
\hline & Error & 210 & 328.8 & & \\
\hline & Between Pop & 4 & 35045.9 & 6.1 & 0.001 \\
\hline & Error & 42 & 5749.4 & & \\
\hline \multicolumn{6}{|c|}{ Flowers } \\
\hline & Within Date & 5 & 800.9 & 27.1 & $<0.001$ \\
\hline & Date $\times$ Pop & 20 & 15.2 & 0.5 & 0.96 \\
\hline & Error & 205 & 29.6 & & \\
\hline & Between Pop & 4 & 27.3 & 0.3 & 0.86 \\
\hline & Error & 41 & 83.9 & & \\
\hline
\end{tabular}

in partridge pea and underlie lower flower production in the field compared to greenhouse grown plants that were not exposed to pollinators. When measured in September 2017 plants in the field produced a mean of 3.6 to 9.8 fruits per plant, yet the mean number of flowers per plant was 1 to 5.6 across these populations (Coltharp and Wallace, unpublished data). Although we observed variation in the date of first flower across latitudes, by the time when all populations were in flower field plants still produced fewer flowers per plant than the greenhouse plants.

We found strong positive correlations in most phenotypic traits measured (Table 4), although shoot height and the number of stems and leaves were negatively correlated. Significant correlation of phenotypic traits is expected if they are developmentally constrained or jointly affect fitness. In a meta-analysis of phenotypic trait correlations, Conner et al. (2014) reported a mean correlation coefficient of ca. 0.5 across many different types of traits and organisms. As suggested by the authors, this level of correlation can be considered the background association of traits needed for organismal function. Lower correlation coefficients may indicate reduced functionality of the whole organism, while higher correlation coefficients may indicate increased fitness for specific trait groups, particularly floral traits. Many of the correlations among the traits we measured in partridge pea are at or above 0.5 (Table 5). Correlation coefficients between number of leaves and other traits were among the highest we found. The number of leaves on a plant has bearing on photosynthetic rate and herbivory, which could strongly influence plant fitness. The number of leaves and final weight were the most strongly correlated with number of flowers, suggesting that more vigorous plants may be likely to have fitness advantage. Other studies have noted positive associations between reproductive traits and those associated with photosynthetic rate, including total plant weight and total reproductive weight in Silene vulgaris (Moench) Garcke (Caryophyllaceae) (Colosi and Cavers 1984).

Significant latitudinal variation was detected in the number of leaves and stems in both the greenhouse and field plants. This pattern was driven by plants from the southernmost population 

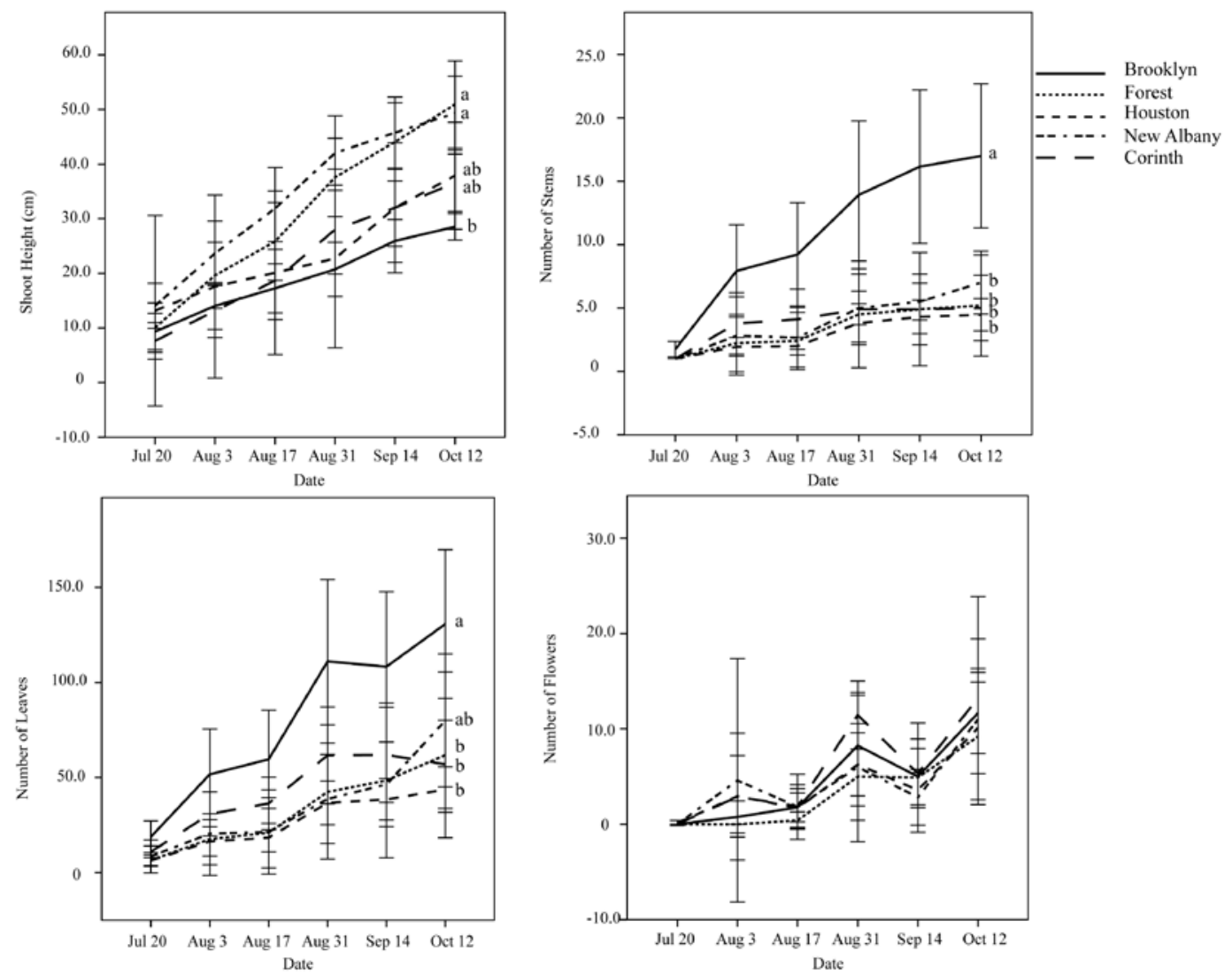

Figure 3. Changes in phenotypic traits of plants from each Mississippi population of Chamaecrista fasciculata (Michx.) Greene (Fabaceae) included in the common garden experiment. Significant differences were found across dates for all traits. Populations exhibiting significant differences in shoot height, number of leaves, and number of stems $(p<0.05)$ are indicated by unlike letters. The number of flowers, which is date-specific rather than cumulative, did not differ significantly across populations.

Table 5. Pearson pairwise correlations of phenotypic traits measured on plants in the common garden experiment of Chamaecrista fasciculata (Michx.) Greene (Fabaceae) from Mississippi.

\begin{tabular}{llllll}
\hline Trait & Stems & Height & Leaves & Flowers & Wet weight \\
\hline Height & $-0.275^{*}$ & & & & \\
Leaves & $0.896^{* *}$ & -0.141 & & & \\
Flowers & $0.307^{*}$ & $0.409^{* *}$ & $0.522^{* *}$ & & \\
Wet weight & $0.527^{* *}$ & $0.523^{* *}$ & $0.709^{* *}$ & $0.738^{* *}$ & \\
Dry weight & $0.497^{* *}$ & $0.587^{* *}$ & $0.681^{* *}$ & $0.762^{* *}$ & $0.985^{* *}$ \\
\hline
\end{tabular}

Height = shoot height; Stems = number of stems; Leaves = number of leaves; Flowers = number of flowers. ${ }^{*}$ Indicates significance at $\mathrm{p}<0.05 ;{ }^{* *}$ indicates significance at $\mathrm{p}<0.01$.

that exhibited the most striking difference in growth form and pubescence, in contrast to other populations that rarely varied significantly for most of the traits measured in the greenhouse and in the field (Figures 2, 3). Environmental heterogeneity and genetic isolation are expected to increase as distance between population increases. As a result of this, populations may be expected to exhibit geographic variation in phenotypic and genotypic traits. Spatial structure can also lead to local 
adaptation, which has often been found in plant species from a variety of ecosystems (Clausen et al. 1948, Antonovics and Bradshaw 1970, Galen et al. 1991, Sork et al. 1993, Galloway and Fenster 2000, Etterson 2004, Leimu and Fischer 2008). Given the wide distribution and varied habitats in which partridge pea occurs, as well as limited seed and pollen dispersal (Fenster 1991), we expected to find geographic variation in phenotypic traits. Through a common garden experiment, we are not able to determine whether the observed variation is adaptive, nor do we know the genes involved in the observed variable traits. Viewed in the context of environmental variation we suggest that several of these traits could be adaptive, given the significant association between latitude and stem height, number of leaves, and number of stems and the finding that stem and leaflet trichome density is not independent of population of origin.

With decreasing latitude, temperature, precipitation, and solar ultraviolet radiation increase (de Frenne et al. 2013). These characteristic patterns in abiotic factors may help to explain associated latitudinal gradients in biological traits that are commonly observed (Kreft and Jetz 2007, de Frenne et al. 2013, Xu et al. 2017). Within Mississippi, temperature and precipitation vary, with southern Mississippi being warmer and wetter compared to northern Mississippi, particularly during the growing season for partridge pea. Mean annual temperature ranges from $18.69^{\circ} \mathrm{C}$ at the lowest latitude to $15.48^{\circ} \mathrm{C}$ at the highest latitude, and annual precipitation ranges from $1,619 \mathrm{~mm}$ in the south to $1,463 \mathrm{~mm}$ in the north, with July precipitation alone being almost $60 \mathrm{~mm}$ more in the southern areas (2.5 min resolution; Fick and Hijmans 2017). Increased branching, shorter stature, and pubescence can be adaptive at higher temperatures as found by Housman et al. (2002) for desert populations of Encelia farinosa Gray ex. Torr. (Asteraceae). Although pubescence mitigates problems encountered with higher temperatures, it can also reduce overall photosynthetic rates. Pubescence was advantageous for E. farinosa because plants also produced a greater number of stems (and hence more leaves) in desert habitats, which maximized photosynthesis (Housman et al. 2002). Given the correspondence between increased branching and greater pubescence found in areas of Mississippi with higher temperatures, a similar trade-off may be occurring in partridge pea populations at low latitudes.

Growth habit and pubescence of partridge pea could also be influenced by interactions with other species. Plant biotic interactions are more numerous and increase in strength with decreasing latitude (Schemske et al. 2009). For example, herbivory increases with decreasing latitude (Pennings and Silliman 2005), perhaps due to milder winters and consistent temperatures that promote greater abundance and diversity of potential herbivores (Janzen 1970, de Sassi and Tylianakis 2012). Because of increased diversity and density of herbivores, plant defenses against herbivores may become stronger at lower latitudes (Schemske et al. 2009, Marquis et al. 2012, Salazar and Marquis 2012). Numerous structural traits, including trichomes and divaricated branching, are important for plant protection against herbivory (Hanley et al. 2007, War et al. 2012). Furthermore, these traits often show latitudinal variation. For example, Abdala-Roberts et al. (2019) found a significant negative correlation between leaf pubescence and herbivory by leaf-chewing insects in Gossypium hirsutum L. (Malvaceae) across latitudes, as well as increased pubescence in drier conditions, thus suggesting that variation in pubescence can be geographically shaped by selection from multiple factors. In Ruellia nudiflora (Engelm. And Gray) Urb. (Acanthaceae) Abdala-Roberts et al. (2016) reported significant latitudinal variation in leaf pubescence, which was not solely determined by herbivore pressure. We have noticed higher rates of leaf damage in partridge pea populations at higher latitudes within Mississippi (Coltharp and Wallace, unpublished data). Notably, these areas also contain plants with less branching and reduced leaf pubescence, which could indicate a defensive role for these traits.

Alternatively, stem branching may be decoupled from leaf pubescence, with the observed variation a response to a different set of factors. For example, light availability has been invoked to explain branching patterns in shrubs and trees in forest habitats (Luken et al. 1995). In Arabidopsis thaliana (L.) Heynh. (Brassicaceae) branching architecture was found to be sensitive to nitrate availability, and variation in plasticity of branching was associated with flower time differences (de Jong et al. 2019). Variation in abiotic factors such as these occur across Mississippi, but additional studies are 
needed to better understand their role in branching architecture of partridge pea. Further studies would be helpful to understand the factors that influence leaflet pubescence and stem branching in southernmost populations of partridge pea, as these may have evolved in response to herbivores, temperature, or some combination of these factors.

Many studies have found evidence of local adaptation in plant species from diverse habitats, but these patterns can vary greatly by species and spatial scale (Knight and Miller 2004, Baughman et al. 2019). Previous studies aimed at detecting local adaptation in partridge pea have had mixed results. Galloway and Fenster (2000) only detected local adaptation in C. fasciculata at distances greater than $1000 \mathrm{~km}$ when considering populations from Maryland, Illinois, and Kansas. These authors suggested that metapopulation processes and temporal environmental variation may reduce potential for this species to become locally adapted. Instead, they suggested that plasticity may act at distances up to $100 \mathrm{~km}$, with adaptation occurring only at larger distances, determined by the scale of colonization (Galloway and Fenster 2000). Similarly, Abdala-Roberts and Marquis (2007) did not find evidence of local adaptation in partridge pea at a small spatial scale using seeds from populations in Missouri and Illinois. They suggested that inconsistent biotic pressures, young age of populations, seed predators, and small spatial scale may underlie the lack a signal of local adaptation in their study. In contrast to these findings, Etterson (2004) was able to find strong evidence of local adaptation in populations originating from Minnesota, Kansas, and Oklahoma, which is a similar spatial scale to that in Galloway and Fenster (2000). She suggested that plants were locally adapted to climatic factors and photoperiod (Etterson 2004). In her study, the southernmost site favored plants with slower reproductive development and more numerous and thicker leaves. Additionally, there was selection towards the mean trait value of the local population for each site studied. Evidence of local adaptation has also been found in C. fasciculata var. macrosperma Fern., which is endemic to freshwater tidal wetlands of Virginia and Maryland, and exhibits increased biomass, larger seeds, and greater shallow root growth in flooded areas over upland forms of C. fasciculata var. fasciculata (Fenster 1997).

Because $C$. fasciculata is an annual and produces an abundance of seeds, rapid evolutionary change in response to selective pressures seemingly could occur rapidly. Our results of trait variation are like Etterson (2004) in that plants from the southernmost populations did begin to flower later than those in northern Mississippi, and we did find that plants from the southernmost population contained more leaves. However, an important distinction between these previous studies and the current one is that the degree of phenotypic variation observed in Mississippi covers a wider selection of traits and is potentially greater in scope compared to higher latitudes. Plants with pubescent leaflets have rarely been reported beyond coastal areas of the southeastern United States (see Pullen 1963 for an extensive review), and taxonomists have repeatedly commented on the greater phenotypic variation of this species on the Coastal Plain. In our study, significant differences in phenotypic variation were not associated with maximum distance between populations from which seeds were collected, but instead were associated with latitude and climatic variation. In summary, these studies would seem to support the hypothesis that partridge pea is rather capable of local adaptation across its range.

Although there is reason to expect local adaptation in functional traits that are potentially associated with temperature regulation, photosynthesis, and defense we also suggest that the spatial structure of phenotypic variation might be influenced by historical demographic factors and colonization patterns. The central-marginal model (Brown 1984) states that marginal or edge populations are expected to harbor less genetic variation and to exhibit higher population differentiation than central populations. Levels of diversity can vary among leading-edge and rear-edge populations. Whereas the former experience loss of variation through founder events (Ibrahim et al. 1996, Hewitt 2000, 2004), rear-edge populations may have low genetic variation due to genetic drift (Dynesius and Jansson 2000). If rear-edge populations remain isolated from conspecific populations, then there is a greater chance that they will become genetically and phenotypically distinct from central populations (Martin and Mckay 2004, Hardie and Hutchings 2010, Lecompte et al. 
2016). The contemporary distribution of partridge pea in the United States extends from the Gulf Coast northward to Minnesota and westward to Texas, but we have little understanding of its phylogeographic history. Irwin and Barneby (1982) hypothesized that the origin of the group containing North American Chamaecrista was upland savanna in tropical eastern South America, with taxa in eastern North America being more recently evolved species that formed as the genus migrated northward. Thus, the Gulf Coast region may be an ancestral area for this species and would be expected to contain rearedge populations. In the Southeast east-west disjunctions have been identified for several taxa (Soltis et al. 2006) but understanding of colonization along latitudinal scales has received less attention. Evidence suggests colonization has often occurred from lower latitudes to higher latitudes (Trapnell et al.2007, Morris et al. 2008, Kim et al. 2018). Our understanding of phenotypic variation and potential for local adaptation would be greatly improved by greater understanding of its relationship of C. fasciculata to Central and South American species and its colonization patterns throughout eastern North America.

Deeper understanding of intraspecific variation has relevance to taxonomy nomenclature and classification. Partridge pea with pubescent leaflets have been recognized by many botanists and named by some. Results from our work support this distinction relative to the more widespread form lacking pubescent leaflets. Given that we do not know whether the variants are reproductively isolated, we suggest maintaining the taxonomic distinction at the subspecific level. We are currently conducting studies to determine the genetic basis underlying the phenotypic differences in growth form and leaflet pubescence. Other studies that aim to test for reproductive compatibility between these variants would also be helpful in fully understanding the reason for and consequence of this variation in the context of the communities in which these plants live. Because plants with the heaviest pubescence occur in the southernmost area of the species distribution in the United States, we hypothesize that this is a response to environmental variation.

\section{ACKNOWLEDGMENTS}

We thank Katie Atkins for assisting in data collection on traits in the field. MH-N was supported by the J. Robert Stiffler Endowment at Old Dominion University.

\section{LITERATURE CITED}

Abdala-Roberts, L. and R.J. Marquis. 2007. Test of local adaptation to biotic interactions and soil abiotic conditions in the ant-tended Chamaecrista fasciculata (Fabaceae). Oecologia 154:315-326.

Abdala-Roberts, L., X. Moreira, S. Rasmann, V. Parra-Tabla, and K.A. Mooney. 2016. Test of biotic and abiotic correlates of latitudinal variation in defences in the perennial herb Ruellia nudiflora. J. Ecol. 104:580-590.

Abdala-Roberts, L., T. Quijano-Medina, X. Moreira, C. Vázquez-González, V. Parra-Tabla, J.C. Berny Mier Y Terán, L. Grandi, G. Glauser, T.C.J. Turlings, and B. Benrey. 2019. Bottom-up control of geographic variation in insect herbivory on wild cotton (Gossypium hirsutum) by plant defenses and climate. Amer. J. Bot. 106:1059-1067.

Ackerman, J.D. 1989. Limitations to sexual reproduction in Encyclia krugii (Orchidaceae). Syst. Bot. 14:101-109.

Antonovics, J. and A.D. Bradshaw. 1970. Evolution in closely adjacent plant populations. VIII. Clinal patterns at a mine boundary. Heredity 25:349-362.

Ashman, T.-L. 1992. Indirect costs of seed production within and between seasons in a gynodioecious species. Oecologia 92:266-272.

Baughman, O.W., A.C. Agneray, M.L. Forister, F.F. Kilkenny, E.K. Espeland, R. Fiegener, M.E. Horning, R.C. Johnson, T.N. Kaye, J. Ott, J.B. St. Clair, and E.A. Leger. 2019. Strong patterns of intraspecific variation and local adaptation in Great Basin plants revealed through a review of 75 years of experiments. Ecol. Evol. 9:6259-6275.

Brown, J.H. 1984. On the relationship between abundance and distribution of species. Amer. Naturalist 124:255-279. 
Clausen, J., D.D. Keck, and W.M. Heisey. 1948. Experimental studies on the nature of species. III. Environmental responses of climatic races of Achillea. Carnegie Institute of Washington publication no. 581. Washington, D.C.

Colosi, J.C. and P.B. Cavers. 1984. Pollination affects percent biomass allocated to reproduction in Silene vulgaris (Bladder Campion). Amer. Naturalist 124:299-306.

Conner, J.K., I.A. Cooper, R.J. La Rosa, S. G. Perez, and A.M. Royer. 2014. Patterns of phenotypic correlations among morphological traits across plants and animals. Philos. Trans., Ser. B 369: 20130246. http://dx.doi.org/10.1098/rstb.2013.0246.

de Frenne, P., B.J. Graae, F. Rodríguez-Sánchez, A. Kolb, O. Chabrerie, G. Decocq, H. de Kort, A. de Schrijver, M. Diekmann, O. Eriksson, R. Gruwez, M. Hermy, J. Lenoir, P. Plue, D.A. Coomes, and K. Verheyen. 2013. Latitudinal gradients as natural laboratories to infer species' responses to temperature. J. Ecol. 101:784-795.

de Jong, M., H. Tavares, R.K. Pasam, R. Butler, S. Ward, G. George, C.W. Melnyk, R. Challis, P.X. Kover, and O. Leyser. 2019. Natural variation in Arabidopsis shoot branching plasticity in response to nitrate supply affects fitness. Plos One Genetics 15: e1008366. https://doi.org/10.1371/journal. pgen.1008366.

de Sassi, C. and J.M. Tylianakis. 2012. Climate change disproportionately increases herbivore over plant or parasitoid biomass. Plos One 7:e40557. https://doi.org/10.1371/journal.pone.0040557.

de Villemereuil, P., O.E. Gaggiotti, M. Mouterde, and I. Till-Bottraud. 2016. Common garden experiments in the genomic era: new perspectives and opportunities. Heredity 116:249-254.

des Roches, S., D.M. Post, N.E. Turley, J.K. Bailey, A.P. Hendry, M.T. Kinnison, J.A. Schweitzer, and E.P. Palkovacs. 2018. The ecological importance of intraspecific variation. Nat. Ecol. Evol. 2:57-64.

Dynesius, M. and R. Jansson. 2000. Evolutionary consequences of changes in species' geographical distributions driven by Milankovitch climate oscillations. Proc. Natl. Acad. Sci. U.S.A. 97:9115-9120.

Etterson, J.R. 2004. Evolutionary potential of Chamaecrista fasciculata in relation to climate change. I. clinal patterns of selection along an environmental gradient in the Great Plains. Evolution 58:1446-1458.

Fenster, C.B. 1991. Gene flow in Chamaecrista fasciculata (Leguminosae) I. Gene dispersal. Evolution 45:398-409.

Fenster, C.B. 1997. Ecotypic differentiation for flood-tolerance and its morphological correlates in Chamaecrista fasciculata. Aquatic Bot. 56:215-231.

Fick, S.E. and R.J. Hijmans, 2017. Worldclim 2: new 1-km spatial resolution climate surfaces for global land areas. Int. J. Climatol. 37:4302-4315.

Forsman, A. 2014. Effects of genotypic and phenotypic variation on establishment are important for conservation, invasion, and infection biology. Proc. Natl. Acad. Sci. USA. 111:302-307.

Galen, C., J.S. Shore, and H. Deyoe. 1991. Ecotypic divergence in alpine Polemonium viscosum: genetic structure, quantitative variation, and local adaptation. Evolution 45:1218-1228.

Galloway, L.F. and C.B. Fenster. 2000. Population differentiation in an annual legume: local adaptation. Evolution 54:1173-1181.

Gao, S.B., L.D. Mo, L.H. Zhang, J.L. Zhang, J.B. Wu, J.L. Wang, N.X. Zhao, and Y.B. Gao. 2018. Phenotypic plasticity vs. local adaptation in quantitative traits differences of Stipa grandis in semi-arid steppe, China. Sci. Rep. 8:3148. https://doi.org/10.1038/s41598-018-21557-w.

Hanley, M.E., B.B. Lamont, M.M. Fairbanks, and C.M. Rafferty. 2007. Plant structural traits and their role in antiherbivore defense. Pl. Ecol. Evol. Syst. 8:157-178.

Hardie, D.C. and J.A. Hutchings. 2010. Evolutionary ecology at the extremes of species' ranges. Environm. Rev. 18:1-20.

Henson, T.M., W. Cory, and M.T. Rutter. 2013. Extensive variation in cadmium tolerance and accumulation among populations of Chamaecrista fasciculata. Plos One 8:e63200. https://doi.org/10.1371/ journal.pone.0063200.

Hewitt, G.M. 2000. The genetic legacy of the Quaternary ice ages. Nature 405:907-913. 
Hewitt, G.M. 2004. Genetic consequences of climatic oscillations in the Quaternary. Philos. Trans., Ser. B 359: 183-195.

Housman, D.C., M.V. Price, and R.A. Redak. 2002. Architecture of coastal and desert Encelia farinosa (Asteraceae): consequences of plastic and heritable variation in leaf characters. Amer. J. Bot. 89:1303-1310.

IBM Corporation. 2016. IBM SPSS Statistics for Windows, Version 24.0. IBM Corporation, Armonk, New York.

Ibrahim, K.M., R.A. Nichols, and G.M. Hewitt. 1996. Spatial patterns of genetic variation generated by different forms of dispersal during range expansion. Heredity 77:282-291.

Irwin, H.S. and R.C. Barneby. 1981. The American Cassiinae. A synoptical revision of Leguminosae tribe Cassieae subtribe Cassiinae in the New World. Mem. New York Bot. Gard. 35:1-918.

Isley, D. 1975. Leguminosae in the United States: II. Subfamily Caesalpinioideae. Mem. New York Bot. Gard. 25:1-228.

Janzen, D.H. 1970. Herbivores and number of tree species in tropical forests. Amer. Naturalist 104:501-28.

Kim, S.H., M.S. Cho, P. Li, and S.C Kim. 2018. Phylogeography and ecological niche modeling reveal reduced genetic diversity and colonization patterns of skunk cabbage (Symplocarpus foetidus; Araceae) from glacial refugia in Eastern North America. Frontiers in Pl. Sci. 9:648. https://doi. org/10.3389/fpls.2018.00648.

Knight, T.M. and T.E. Miller. 2004. Local adaptation within a population of Hydrocotyle bonariensis. Evol. Ecol. Res. 6:103-114.

Kovnat, G.D. and J.M. Porter. 2016. A common garden experiment illustrating phenotypic plasticity in an ecotone population of Deinandra fasciculata (Asteraceae). Crossosoma 42:37-47.

Kreft, H. and W. Jetz. 2007. Global patterns and determinants of vascular plant diversity. Proc. Natl. Acad. Sci. U.S.A. 104:5925-5930.

Lecompte E., M.-A. Bouanani, A. Magro, and B. Crouau-Roy. 2016. Genetic diversity and structure across the range of a widely distributed ladybird: focus on rear-edge populations phenotypically divergent. Ecol. Evol. 6:5517-5529.

Leimu, R. and M. Fischer. 2008. A meta-analysis of local adaptation in plants. Plos One 3:e4010. https://doi.org/10.1371/journal.pone.0004010.

Luken, J.O., T.C. Tholemeier, B.A. Kunkel, and L.M. Kuddes. 1995. Branch architecture plasticity of Amur Honeysuckle (Lonicera macackii (Rupr.) Herder): initial response in extreme light environments. Bull. Torrey Bot. Club 122:190-195.

Marquis, R.J., R.E. Ricklefs, and L. Abdala-Roberts. 2012. Testing the low latitude/high defense hypothesis for broad-leaved tree species. Oecologia 169:811820.

Martin, P.R. and J.K. Mckay. 2004. Latitudinal variation in genetic divergence of populations and the potential for future speciation. Evolution 58:938-945.

Martin, R.E., G.P. Asner, and L. Sack. 2007. Genetic variation in leaf pigment, optical and photosynthetic function among diverse phenotypes of Metrosideros polymorpha grown in a common garden. Oecologia 151:387-390.

Morris, A.B., S.M. Ickert-Bon, D.B. Brunson, D.E. Soltis, and P.S. Soltis. 2008. Phylogeographical structure and temporal complexity in American sweetgum (Liquidambar styraciflua; Altingiaceae). Mol. Ecol. 17:3889-3900.

Pennings, S.C. and B.R. Silliman. 2005. Linking biogeography and community ecology. Latitudinal variation in plant-herbivore interaction strength. Ecology 86:23102319.

Pigliucci, M., C.J. Murren, and C.D. Schlichting. 2006. Phenotypic plasticity and evolution by genetic assimilation. J. Exp. Biol. 209:2362-2367.

Pullen, T.M. 1963. The Cassia fasciculata complex (Leguminosae) in the United States. PhD dissertation, University of Georgia, Athens, Georgia.

Rios, R.R., R.J. Marquis, and J.C. Flunker. 2008. Population variation in plant traits associated with ant attraction and herbivory in Chamaecrista fasciculata (Fabaceae). Oecologia 156:577-588. 
Robertson, K.R. and Y.-T. Lee. 1976. The genera of Caesalpinioideae (Leguminosae) in the southeastern United States. J. Arnold Arbor. 57:153.

Salazar, D. and R.J. Marquis. 2012. Herbivore pressure increases toward the equator. Proc. Natl. Acad. Sci. U.S.A. 109:12616-12620.

Schemske, D.W., G.G. Mittelbach, H.V. Cornell, J.M. Sobel, and K. Roy. 2009. Is there a latitudinal gradient in the importance of biotic interactions? Annual Rev. Ecol. Evol. Syst. 40:245-269.

Soltis, D.E., A.B. Morris, J.S. McLachlan, P.S. Manos, and P.S. Soltis. 2006. Comparative phylogeography of unglaciated eastern North America. Mol. Ecol. 14:4261-4293.

Sork, V.L., K.A. Stowe, and C. Hochwender. 1993. Evidence for local adaptation in closely adjacent subpopulations of northern red oak (Quercus rubra L.) expressed as a resistance to leaf herbivores. Amer. Naturalist 142:928-936.

Stanton, M.L., J.K. Bereczky, and H.D. Hasbrouck. 1987. Pollination thoroughness and maternal yield regulation in wild radish, Raphanus raphanistrum (Brassicaceae). Oecologia 74:68-76.

Trapnell, D.W., J.P. Schmidt, P.F. Quintana-Ascencio, and J.L. Hamrick. 2007. Genetic insights into the biogeography of the southeastern North American endemic, Ceratiola ericoides (Empetraceae). J. Heredity 98:587-593.

USDA, NRCS. 2019. The PLANTS Database (http://plants.usda.gov, 28 June 2019). National Plant Data Team, Greensboro, NC 27401-4901 USA.

War, A.R., M.G. Paulraj, T. Ahmad, A.A. Buhroo, B. Hussain, S. Ignacimuthu, and H.C. Sharma. 2012. Mechanisms of plant defense against insect herbivores. Plant Signaling and Behavior 7:1306-1320.

Weakley, A.S. 2015. Flora of the southern and mid-Atlantic states, working draft of 21 May 2015. University of North Carolina Herbarium, Chapel Hill, North Carolina.

Xu, M., L. Ma, J. Yanyan, and M. Liu. 2017. Integrating the effects of latitude and altitude on the spatial differentiation of plant community diversity in a mountainous ecosystem in China. Plos One 12: e0174231. https://doi.org/10.1371/journal.pone.0174231. 